\title{
MORABA - Overview on DLR's Mobile Rocket Base and Projects
}

\author{
L. Altenbuchner ${ }^{1}$, J. Ettl ${ }^{2}$, M. Hörschgen ${ }^{3}$, W. Jung ${ }^{4}$, R. Kirchhartz ${ }^{5}, \underline{\text { A. Stamminger }}{ }^{6}$ and P. Turner ${ }^{7}$ \\ DLR Mobile Rocket Base, Oberpfaffenhofen, 82234 Wessling, Germany
}

\begin{abstract}
Mobile Rocket Base (MORABA), a division of the Space Operations and Astronaut Training Department of DLR (Deutsches Zentrum für Luft- und Raumfahrt) provides the national and international scientific community with the opportunity to prepare and implement rocket- and balloon-borne experiments. The fields of research include aeronomy, astronomy, geophysics, material science and hypersonic research and are conducted in cooperation with a variety of international partners. In addition satellite missions can be supported by mobile tracking radars for trajectory determination and TT\&C mobile ground stations. MORABA also offers a number of mechanical and electrical systems for use on rocket, balloon and short term satellite missions. During the last four decades more than 250 campaigns have been performed in Antarctica, Australia, Brazil, France, Greenland, India, Italy, Japan, Norway, Spain, Sweden and USA. Depending on the scientific objective, an appropriate launch range is selected and complemented or fully equipped with MORABA's mobile infrastructure, such as launcher, telemetry and tracking stations. MORABA supplies the suitable converted military surplus or commercial launch vehicles, as well as all necessary mechanical and electrical subsystems to the customers. This paper gives an overview of the MORABA infrastructure for sounding rocket launching and satellite TT\&C. A short survey of MORABA projects of the last two years and the next two years is also provided.
\end{abstract}

\section{Introduction}

$\mathrm{T}$ HE Mobile Rocket Base (MORABA) was founded in 1967 as part of the Max Planck Society (Arbeitsgruppe für Weltraumforschung) under the initiative of Professor Reimar Lüst. MORABA was later integrated into DLR and is based in Oberpfaffenhofen, Germany.

MORABA's main task is to support the national and international research community in the preparation and execution of sounding rocket- and balloon-borne experiments. These cover a variety of scientific fields, such as atmospheric physics, astronomy, microgravity and linear acceleration experiments, hypersonic research, technology testing and education. By providing and operating mobile infrastructure (TT\&C and rocket launchers), it is possible to perform complex scientific missions at almost any location that might be required by the experiment. Most frequently, launches are conducted from Esrange (Sweden), Andøya Rocket Range and Spitzbergen (Norway), Natal and Alcântara (Brazil) as well as Biscarosse (France), but remote locations like Antarctica or Woomera (Australia) have also been used. Minimal infrastructure is required to establish a launch site at other desired locations.

The development of new launch vehicle systems to meet the scientific requirements of the various missions constitutes a key capability of MORABA. Military surplus rocket motor systems are converted for the use as sounding rockets and commercially available systems are acquired as necessary. The cost-effective combination of these motors to make up the desired launch vehicle is a key competence of MORABA. A long standing collaboration with our partners in Brazil (DCTA and IAE, see section VI B) offers a uniqe ability to directly influence the design of new rocket motor systems for research purposes.

\footnotetext{
${ }^{1}$ Team Leader of MORABA Mobile Infrastructure, DLR MORABA, ludwig.altenbuchner@dlr.de.

2 Team Leader of MORABA Electrical Flight Systems, DLR MORABA, josef.ettl@dlr.de.

${ }^{3}$ Team Leader of MORABA Mechanical Flight Systems, DLR MORABA, marcus.hoerschgen@dlr.de.

${ }^{4}$ Team Leader of MORABA Launch Systems, DLR MORABA, wolfgang.jung@dlr.de.

${ }^{5}$ MORABA Launch Systems, DLR MORABA, rainer.kirchhartz@dlr.de.

${ }^{6}$ MORABA Business Development, DLR MORABA, andreas.stamminger@dlr.de.

${ }^{7}$ Head of MORABA, DLR MORABA, peter.turner@dlr.de.
}

1

American Institute of Aeronautics and Astronautics 


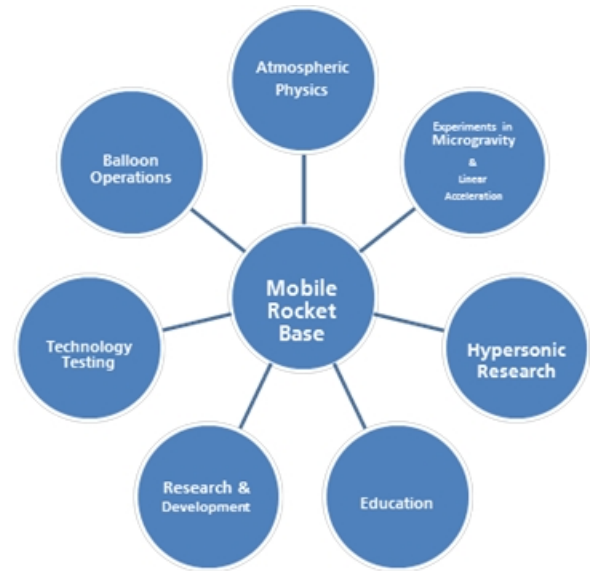

Figure 1. MORABA Operation, Research \& Development Fields
A further objective of MORABA is the development, fabrication and testing of commercially unavailable mechanical and electrical components and systems for sounding rockets and balloons as well as for short duration satellite missions.

The key work areas of MORABA are shown in Figure 1. In accordance with its key work areas, MORABA is structured into four groups as shown in Figure 2, covering telemetry and RADAR for status and trajectory information, electronic and mechanical flight systems as well as launch services and flight dynamics.

MORABA is one of a few institutions worldwide which offers the science community all necessary infrastructure and expertise to perform sounding rocket based missions. The mobile infrastructure of MORABA meets highest international standards and enables even very demanding scientific missions. MORABA is ISO 9001 and OHSAS 18001 certified for "Preparation and Conduct of Sounding Rocket Missions for various Scientific Applications" by Bureau Veritas.

Primary customers of MORABA's expertise and facilities are universities and research institutions, as well as national and international organizations and industry. The majority of the projects with MORABA participation are funded by the German Federal Ministry of Economics and Technology, the DLR Space Administration and ESA.

\section{Mission Preparation and Performance}

For missions conducted within the national space program, MORABA is usually contacted by the primary investigator in the early stage of a project. MORABA provides assistance in defining the mission objectives, selecting suitable sounding rocket vehicles and optimum launch locations. The necessary electrical and mechanical subsystems that are required to meet the mission objectives (e.g., telemetry, recovery) are identified as vital components for the mission scenario. Finally, MORABA provides preliminary costings and implementation plans as input for the scientist's project proposal to the funding agencies. Aside from national scientists, MORABA is contacted by commercial customers in response to conference presentations, international contacts or cooperation..

This section describes the usual workflow for the preparation and conduct of a typical sounding rocket or balloon mission from project acquisition to vehicle launch.

\section{A. Mission Management and Range Coordination}

Prior to any mission, negotiations with range authorities are conducted to obtain the necessary launch permissions, to define the local infrastructure facility requirements and to determine logistics requirements. Depending on the range location and existing instrumentation, an optimal ground station configuration and ground support equipment setup is defined. Any deficiencies are supplemented by MORABA mobile equipment. Where required, comprehensive self-contained launch facilities are made available for deployment at remote locations, requiring only minimal on-site preparations.

\section{B. Electrical and Mechanical Manufacturing}

MORABA has a broad experience in the design and manufacturing of complete vehicle systems and is able to provide ready-to-fly solutions to sounding rocket- and balloon-borne scientific experiments.

Depending on the capability of the participating organization or industry, the necessary components for a complete vehicle are

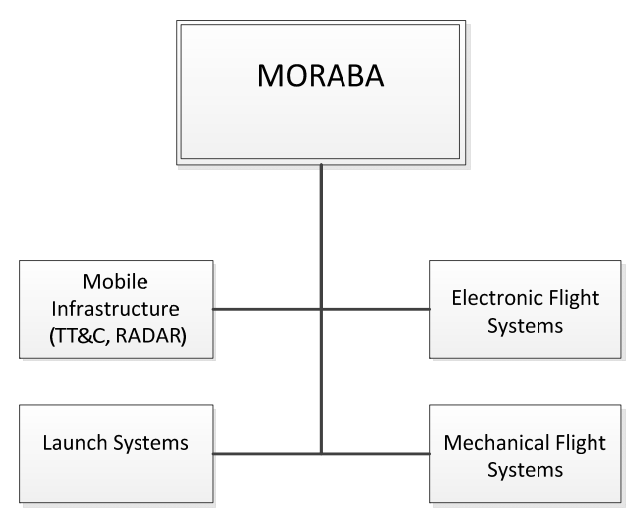

Figure 2. MORABA Organization

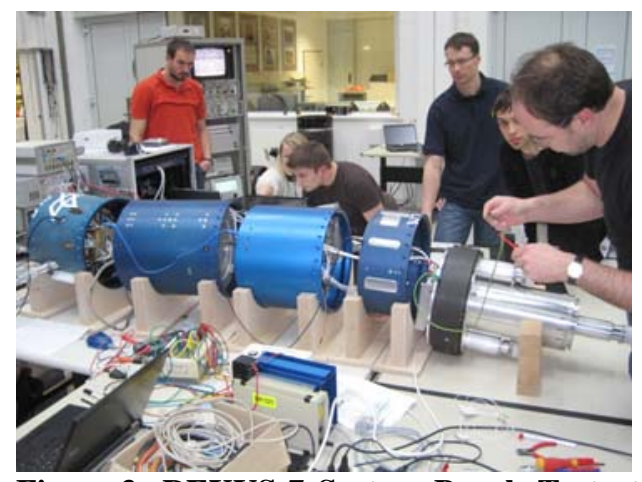

Figure 3. REXUS-7 System Bench Test at DLR laboratories ${ }^{6}$ 
designed and manufactured to the needs of the mission. The spectrum ranges from onboard processor systems, pyrotechnic ignition systems to all kinds of mechanical flight systems.

\section{Assembly, Integration and Testing}

A large variety of sounding rocket payloads and components can be assembled, integrated and tested in the MORABA laboratories, see Figure 3. All necessary equipment and test setups are available to verify transmitter and receiver systems as well as scientific and support system data integrity. Facilities are available to test rate or attitude control systems for a wide range of payloads, including three axis air bearing systems. This allows realistic calibration and verification of the pointing accuracy and the required manoeuvers during the ballistic flight phase in the heterosphere $(>100 \mathrm{Km})$. To facilitate the testing process, dedicated or generic electric ground support equipment is built. For environmental testing, payload balancing and determination of the payload's physical properties, MORABA uses industrial test facilities (EADS Astrium, IABG and the Universität der Bundeswehr in München, Germany ${ }^{8}$ ).

\section{Launch Campaign}

After the successful completion of the bench test, flight simulation test and the environmental tests, all necessary equipment, mobile stations and flight hardware are transported to the selected launch location. Station assembly, motor preparation and payload integration are performed in parallel to reduce the time-to-launch. After completion of the preparation phase, an intensive test period follows to ensure the readiness of all participating organizations and flight systems.

After the test countdown, one or more so called "hot" countdowns are needed to launch the rocket vehicle. The number of countdowns is, besides potentially appearing technical problems, dependent on the weather conditions and scientific constraints. For ionosphere research, certain phenomena like aurora borealis are necessary, to provide the proper scientific conditions for the deployed experiments. In the case of microgravity missions, the launch opportunity is mainly influenced by local weather conditions. After the parachute recovery system sequence and the safe landing of the payload, it is retrieved by helicopter or ship and brought back to the range.

\section{E. Pre- and Post-Flight Mission Analysis}

A major part in the preparatory phase of launching sounding rockets is the pre-flight mission analysis. Depending on the physical properties of the payload and the selected launch vehicle, an iterative analytical process is started to tune and verify the required flight performance with regards to trajectory, stability, heating and re-entry. For range safety and recovery purposes, a dispersion analysis is also performed.

After the flight, all available flight data from various sources, such as RADAR, slant-range, housekeeping data inclusive inertial platform navigation and GPS data are processed and compared to the predicted values. Any deviations and anomalies are investigated and if necessary design and procedure changes are implemented.

\section{Infrastructure}

MORABA has all necessary mobile infrastructures to setup and support worldwide sounding rocket missions. Already during the design of the various stations, special attention was given to mobility and suitability for the extreme environmental conditions encountered at the potential launching sites.

\footnotetext{
${ }^{8}$ University of the German Federal Armed Forces
} 


\section{A. Telemetry and Telecommand}

MORABA maintains and operates two fully containerized mobile telemetry and telecommand stations in the Sband frequency spectrum, see Figure 4 . These stations can be set up at any electrical developed site on the planet. They are self-contained and adaptable to a variety of configurations. Multiple telemetry and TV links can be supported simultaneously. All necessary equipment, for demodulation and recording of FM, PM PCM and real time TV signals is included in the stations. Signal decommutation and conditioning is also performed. Real time quick look and post flight presentations is available. Each station is equipped with all necessary instrumentation and support electronics to track and command sounding rockets, balloons or satellites.

\section{B. RADAR Tracking}

Beside slant-range data that is made available by the telemetry station and the GPS position data in the vehicles housekeeping data, a mobile instrumentation RADAR (RIR-774C) that operates in the C-band frequency spectrum allows precise trajectory determination for scientific and safety related purposes, see Figure 5 .

Tracking data are used for real-time prediction of the expected impact point during the ascent of a sounding rocket. Based on this information the range-safety officer can decide to destruct the rocket in the case of a deviation from the nominal trajectory if the vehicle is equipped with a destruct system. Sophisticated software packages are available for post flight data evaluation, which is essential for the processing and altitude correlation of many scientific experiments.

\section{Monorail Launcher}

For truly independent launch operations at remote locations, MORABA maintains and operates one mobile sounding rocket launcher system, see Figure 6. This monorail launcher is used for vehicles with a mass of up to six tons. The launcher is remotely controlled from the launch control room. For weather and wind protection during the preparation phase, the launcher can be covered by a tent which is movable on railway tracks.

\section{Laboratory}

At its home base in Oberpfaffenhofen, Germany, MORABA maintains a dedicated laboratory area with various technical test facilities (i.e. thermalvacuum test chamber, three-axis air bearing) and checkout systems. Bench tests and flight simulation tests are performed in the MORABA laboratory.

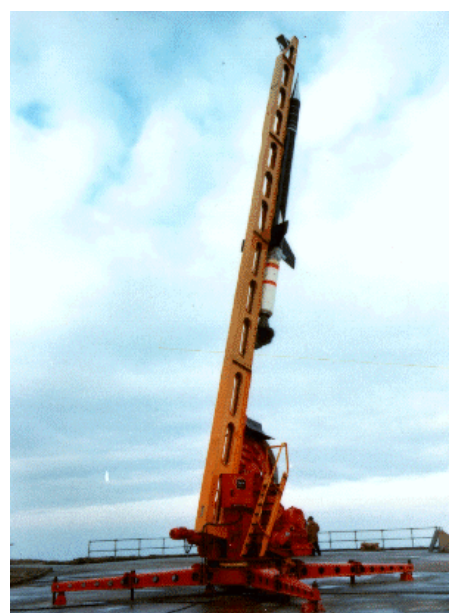

Figure 6. Monorail Launcher for Sounding Rockets

\section{Sounding Rocket and Balloon Mission Portfolio}

In the following chapter the most significant missions in the last five years and the upcoming five years are described. During the last five years more than 40 sounding rockets and 10 balloon flights have been launched with participation or within a "flight ticket" of MORABA from various locations worldwide. Only major missions are addressed in the following subchapters.

\section{A. Atmospheric Research}

Every day, the Earth's atmosphere is hit by $10-100$ tons of meteoric material which largely ablates in the altitude range between 70 and $100 \mathrm{~km}$. Meteoric smoke particles have been proposed to play a major role in a variety of atmospheric processes. The primary

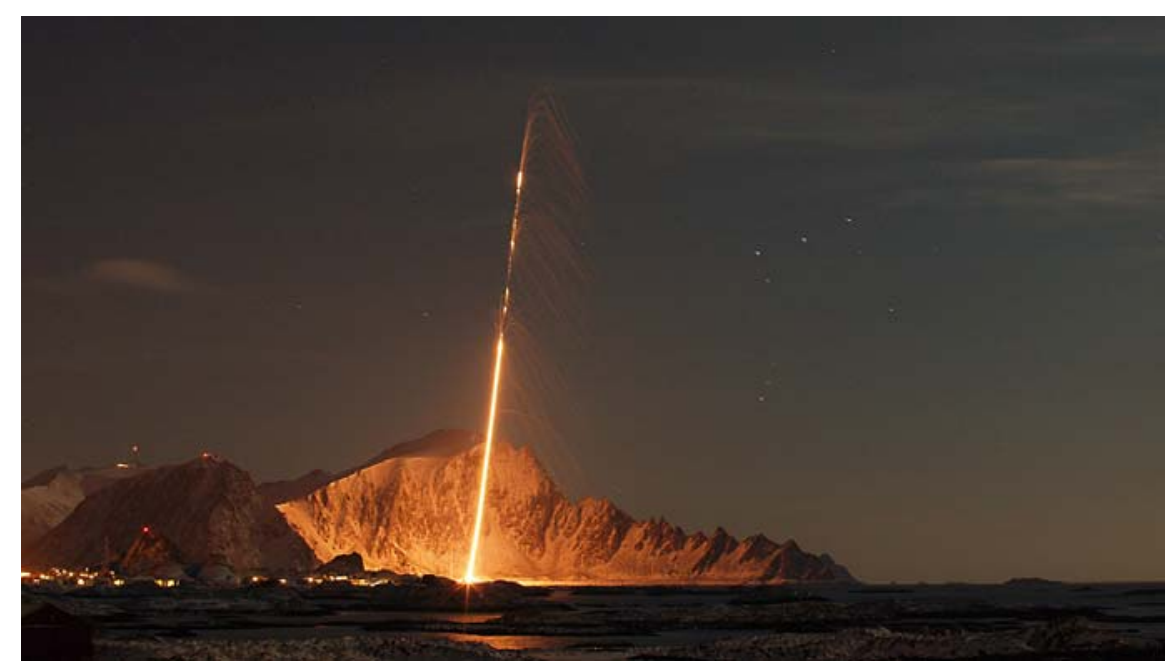

Figure 7. ECOMA Launch (Kjell Bjarne Petterson)

American Institute of Aeronautics and Astronautics 
scientific goal of the ECOMA (Existence and Charge State of Meteoric Dust Grains in the Middle Atmosphere) project was to determine the number density and altitude distribution of meteoric smoke particles in the middle atmosphere. Figure 7 shows a launch of ECOMA in 2010. This project was a bilateral project between Germany and Norway involving a total of 9 sounding rockets distributed over four campaigns from Andøya Rocket Range from 2006 to $2010^{1,2,3,4}$.

A new atmospheric research project with two rockets that will be launched in the next years is WADIS (Wellenausbreitung und Dissipation in der Mittleren Atmosphäre).

\section{B. Microgravity Missions}

Physical experiments in Earth-based laboratories are very often negatively influenced by gravity. Material physics studies, for example, various processes in metallic alloys on an atomic scale. The corresponding experiments require "weightlessness" for high quality results. The suborbital parabolic trajectory of a sounding rocket offers experimental time up to 13 minutes under microgravity conditions. Figure 8 shows the achievable microgravity time versus apogee altitude. The different microgravity programs and projects are marked with different colors.

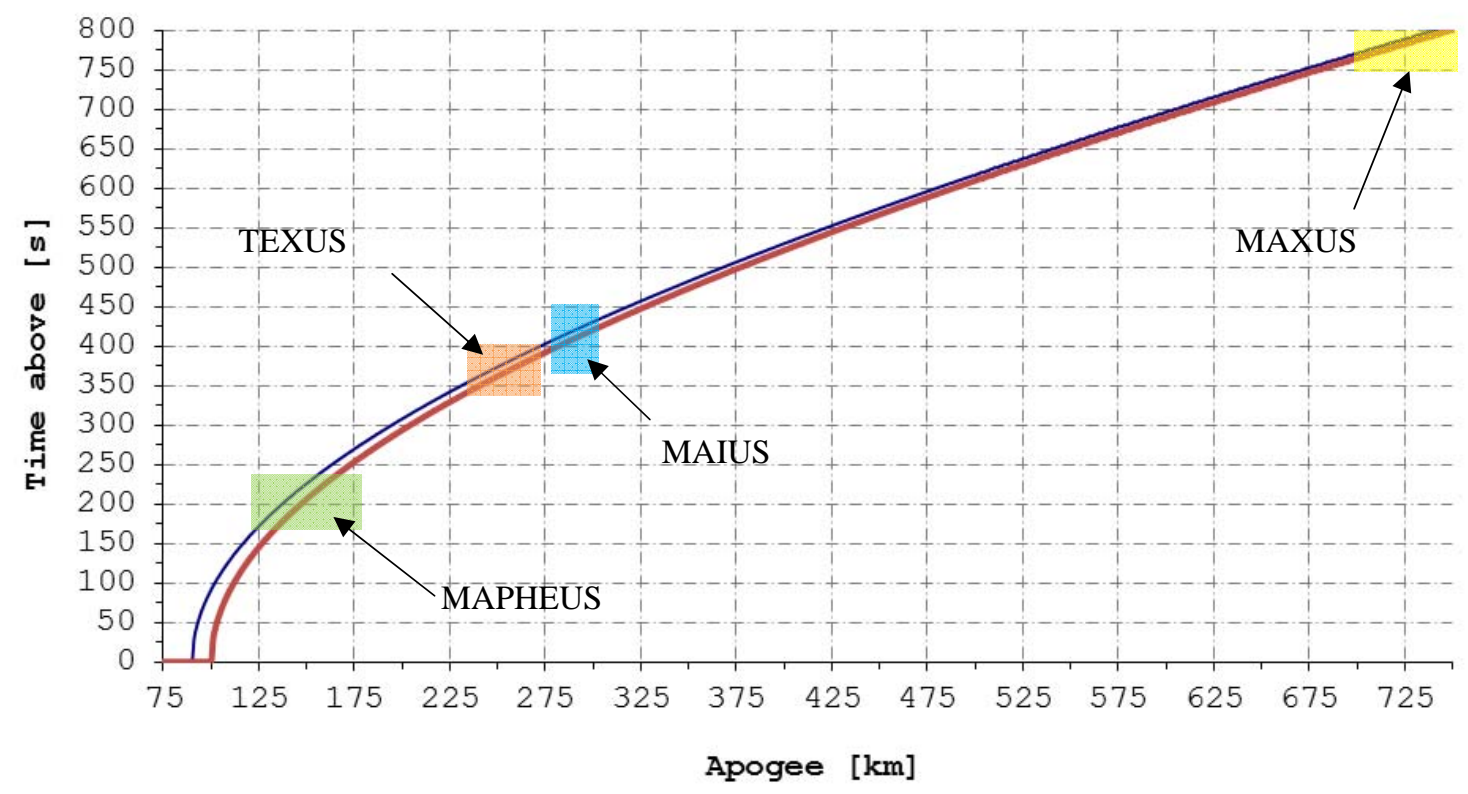

\begin{tabular}{|c|}
\hline Time $>90 \mathrm{~km}[\mathrm{~s}]$ \\
\hline
\end{tabular}

Figure 8. Achievable microgravity time vs. apogee altitude of sounding rocket programs

The TEXUS sounding rocket program (Technologische Experimente Unter Schwerelosigkeit) was initiated in 1976 by the German Ministry of Research and Development. Beginning with TEXUS launches in 1988 the program was commercialized and EADS Astrium has taken the overall responsibility.

MASER is an ESA sounding rocket program with an international participation of industry and science community.

The MAXUS long-duration sounding rocket program is a joint venture of EADS and SSC. This program was initiated in 1990 to extend the microgravity duration capability in Europe to 13 minutes. For MAXUS, a single-stage solid-fuel Castor-4B rocket motor is used to launch a gross payload of typically $800 \mathrm{~kg}$ to an apogee of about 715 $\mathrm{km}$.

For all three programs, MORABA provides essential sounding rocket sub-systems as well as the operation of its mobile ground stations. 5 TEXUS rockets, 2 MASER rockets and 1 MAXUS rocket have been launched in the last five years. 
MAPHEUS (Materialphysikalische Experimente unter Schwerelosigkeit), a DLR research rocket program, provides microgravity environment to DLR material physics payloads. On an annual basis, a MAPHEUS rocket is launched into space to approximately $150 \mathrm{~km}$ altitude. The payload then experiences 3.5 minutes of microgravity before it re-enters the Earth's atmosphere.

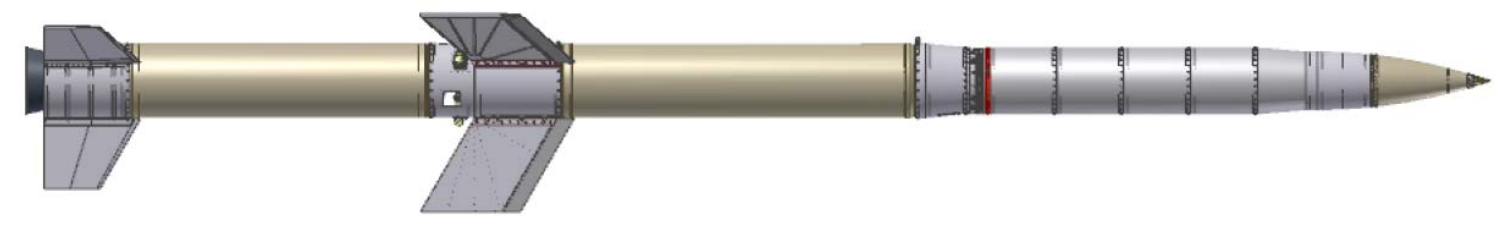

Figure 9. MAIUS-1 Vehicle consisting of a VSB-30 rocket motor assembly and payload.

MAIUS, a matter-wave interferometer that will be launched on a sounding rocket, will generate the first BEC (Bose-Einstein-Condensate) in space and investigate it over a lengthy period of time. Carried by a research rocket especially configured by MORABA, see Figure 9, MAIUS is scheduled to take off from Esrange near Kiruna in the north of Sweden within the next three years. During the microgravity phase of the flight, which will last for several minutes, researchers hope to enter territory that has not been explored so far in quantum physics experiments. To put the matter in perspective - under normal gravity, a BEC can be maintained in a laboratory for no longer than a few fractions of a second. This is why physicists regard this rocket flight as a milestone. During the prolonged phase of microgravity, they will be able to generate not one but several BECs in succession and study them for a period that is much longer than anything that has been achieved so far - a project that is unique worldwide ${ }^{5}$.

\section{Testbed for Hypersonic Research}

In addition to the regular microgravity and atmospheric research programs, there is a growing interest in the use of sounding rockets for performing complex flight experiments in the field of hypersonic research. In contrast to hypersonic wind tunnels, sounding rockets can provide up to one minute of Mach 10 conditions for relatively large experiments. This application requires new classes of vehicles and sub systems which are not readily available on the market.

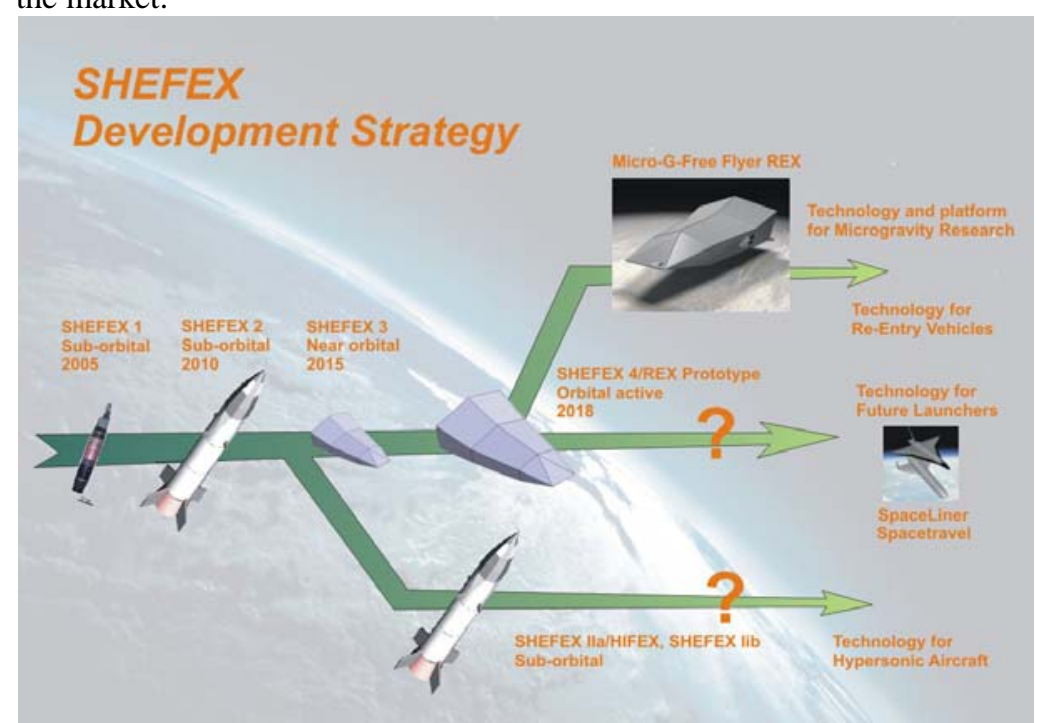

Figure 10. The SHEFEX Development Strategy (DLR)
With the launch of SHEFEX-1 (Sharp Edge Flight Experiment), the DLR MORABA demonstrated its capability to provide a cost-effective platform for hypersonic research during the reentry phase of sounding rocket vehicles.

The goal of the SHEFEX program is to test the most cost effective reentry technology in a flight experiment. To perform the test, the capsule is placed on top of a sounding rocket. SHEFEX-1 was launched in 2005 from Norway. With a length of 12.6 meters, SHEFEX-2 will be launched on a Brazilian two-staged S40/S44 rocket to achieve a higher velocity. Moreover, in contrast to its predecessor, SHEFEX-2 has small wings known as canards, which enable the craft to be maneuvered. From Andøya, SHEFEX-2 should reach an altitude of 200 kilometers. For the researchers, the interesting part begins when it re-enters the Earth's atmosphere with a velocity of more than Mach 10. Then the payload will land in the Norwegian Sea using a parachute recovery system with flotation capability.

The hypersonic research programs HIFiRE (Hypersonic International Flight Research Experimentation) and SCRAMSPACE are two of the international hypersonic research collaborations that are supported by MORABA. The HIFiRE program entails the launch of up to nine research payloads with sounding rockets ${ }^{8}$, of which MORABA provides launch services for four sounding rockets. The SCRAMSPACE program involves the launch of one

6

American Institute of Aeronautics and Astronautics 
sounding rocket to lift a free-flying scramjet payload to its experimental window ${ }^{9}$. This launch service provision entails the procurement, preparation and launch of the rocket motor systems and the necessary hardware, telemetry, RADAR and flight safety support. The special requirements for the experimental payloads and trajectory parameters in missions for hypersonic research result in non-typical vehicle configurations where special attention must be paid to launch vehicle stability and integrity as well as performance.

In parallel MORABA began to support the development of the Brazilian rocket VLM-1 (Veículo Lançador de Microsatélites) that is capable to launch the SHEFEX-3 vehicle to a near orbital trajectory, see Figure 11. The SHEFEX-3 vehicle will be separated from the payload in the heterosphere and autonomously re-enter the atmosphere. The complete SHEFEX development strategy of DLR is shown in Figure 10.

\section{Education}

The REXUS/BEXUS program allows students from universities and higher education colleges across Europe to carry out scientific and technological experiments on research rockets and balloons. Each year, two rockets and two balloons are launched, carrying up to 20 experiments designed and built by student teams.

REXUS experiments are launched on an unguided, spin-stabilized rocket powered by an Improved Orion motor with $290 \mathrm{~kg}$ of solid propellant. It is capable of taking $40 \mathrm{~kg}$ of student experiment modules to an altitude close to $100 \mathrm{~km}$, see Figure 12. The vehicle has a length of approximately $5.6 \mathrm{~m}$ and a body diameter of $356 \mathrm{~mm}$. BEXUS experiments are lifted by a balloon with a volume of $12000 \mathrm{~m}^{3}$ to a maximum altitude of $35 \mathrm{~km}$, depending on total experiment mass (40-100 kg). The typical flight duration is 2-5 hours.

The REXUS/BEXUS program is realized under a bilateral Agency Agreement between the German Aerospace Center (DLR) and the Swedish National Space Board (SNSB). The Swedish share of the payload has been made available to students from other European countries through a collaboration with the European Space Agency (ESA). EuroLaunch, a cooperation between the Esrange Space Center of SSC and MORABA, is responsible for the campaign management and operations of the launch vehicles. Experts from ESA, SSC and DLR provide technical support to the student teams throughout the project. REXUS and BEXUS are launched from Esrange, Sweden.

In winter 2010, DLR launched a support program for students to develop, build and launch their own rockets. The program goes by the acronym STERN (Studentische Experimental-RaketeN). The program adresses at all German universities which offer courses in aerospace technology. The rockets should have a small telemetry system to transmit key trajectory and housekeeping data back to Earth during flight. The rockets may be propelled by a solid-fuel, liquid-fuel, hybrid or steam motor. In order to teach students engineering and science and to put their technical knowledge to the

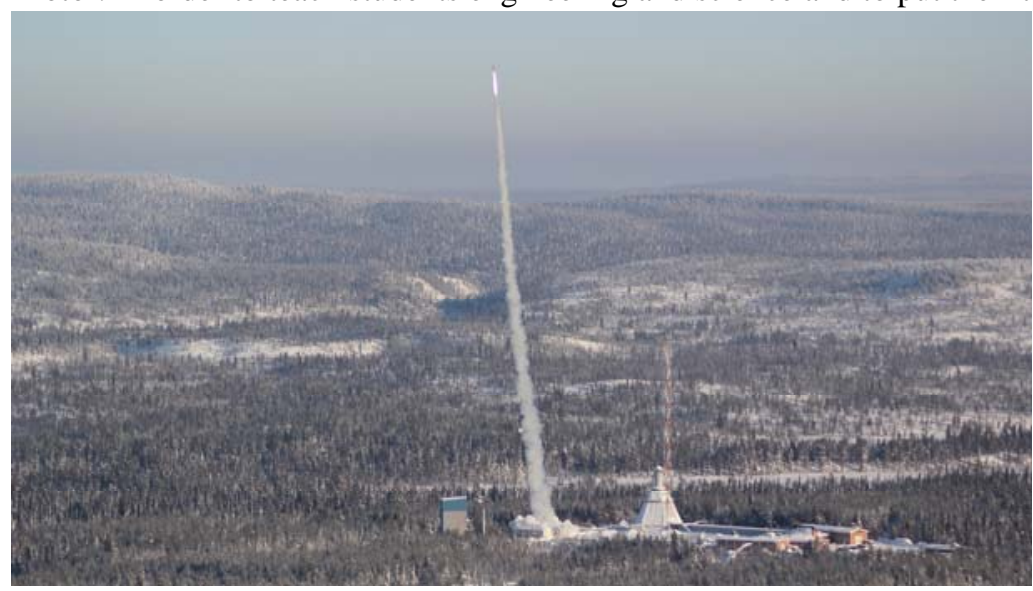

Figure 12. REXUS-11 Lift-Off (DLR)

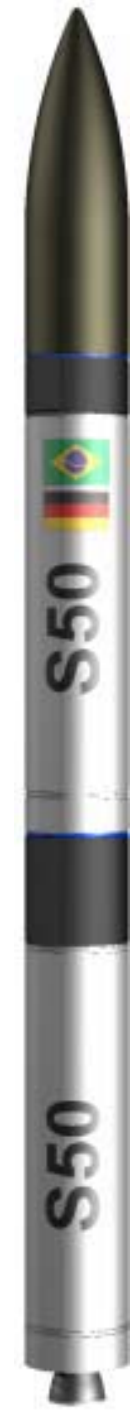

in their studies, there are no altitude restrictions except the normal range range $\mathbf{S H E F}$

Figure 11. VLM-1

Rocket for restrictions. The program will run for up to three years, depending on the university and the scope of the project. At the end of the project, the result should be a flight-capable rocket. Some of the rockets will be launched from the Esrange Space Center at Kiruna, in Sweden. To break the European altitude record could be a long-term objective of the DLR program.

\section{E. Research \& Development}

Major achievements in recent years have been the implementation and qualification of the new rocket vehicle VSB-30, a joint development of the Brazilian institution IAE (Instituto de Aeronaútica e Espaço) together with DLR 
MORABA, which was successfully introduced in the European microgravity programs TEXUS and MASER. New recovery systems were developed in cooperation with Kayser-Threde. In cooperation with SSC a new service system was developed and implemented into the REXUS (Rocket Experiments for University Students) and MAPHEUS program. These modern sounding rocket systems together with the Brazilian VSB-30 vehicle will enable cost effective and short lead time access to a microgravity environment in order to qualify and flight test experiments for the International Space Station (ISS) in parallel to independent missions. With the joint development of the VLM-1, MORABA will be capable to offer a launch vehicle for complex hypersonic re-entry missions.

\section{Technologies for Satellite Missions}

Many subsystems that have originally been developed and employed for sounding rocket applications proved to be attractive for cost-effective, short duration satellite projects. The harsh environment during a sounding rocket launch with its enormous acceleration and vibration profile encouraged further investigations. Radiation related problems could be successfully answered with dedicated tests as reliable data for off-the-shelf components are not available. It could be demonstrated that "Sounding Rocket Technology" is applicable to many short duration satellite projects.

This was first demonstrated as part of the EXPRESS re-entry mission, for which MORABA developed the complete on board TT\&C-system and deployed its mobile telemetry, telecommand and radar stations at the remote Tjaliri site, Australia.

For the BIRD micro-satellite MORABA has developed, manufactured and tested the onboard TM/TC unit including the RF transmission and receiving and antenna system. Originally designed for a life time of less than two years, these systems are still operational after 10 years in orbit. Additionally, well proven PCM data handling subsystems and command logic have been transferred into the spacecraft onboard computer. Furthermore, the mobile S-Band telemetry and command stations were integrated into a ground station concept and used for the first acquisition of the satellite after its launch from India.

\section{International Cooperation}

\section{A. EuroLaunch}

On December $8^{\text {th }}$, 2003 DLR and SSC have signed a cooperation agreement concerning joint activities in the fields of sounding rockets and balloons. This agreement was a continuation and strengthening of an agreement from 1994. The aim of this agreement is to establish a frame for the coordination of their activities, the exchange in the provision of services for sounding rockets and balloons activities towards third parties, with a view to consolidate competence of personnel and utilization of facilities and equipment for the services currently provided by their technical centers SSC Esrange and DLR MORABA. Successful teamwork has been demonstrated with launches of the student rockets REXUS and student balloons BEXUS ${ }^{7}$.

\section{B. DCTA/IAE}

A frame agreement between the governments of the Federal Republic of Germany and the Federative Republic of Brazil on cooperation in the field of scientific research and technology development was signed as early as 1969. By now MORABA looks back on a long history of joint sounding rocket projects with DCTA (Departamento de Ciência e Tecnologia Aeroespacial) and IAE. Many German sounding rocket missions have been performed from the Brazilian CLBI and CLA launch sites. A regular exchange of personnel within various projects has led to a broad competence, reaching from designing and qualifying complete sounding rocket vehicles to implementing state of the art rocket flight design and analysis programs.

\section{Conclusion \& Outlook}

Sounding rockets and balloons will continue to provide a flexible, cost and time effective platform for various fields of scientific research for experiments qualification and for verification measurements. Beside the development of new vehicles for hypersonic research another challenge is the continuously increasing data rate of new experiments and the bandwidth of the telemetry and telecommand systems. The need of teleoperations on experiments during a flight mission and the provision of real time telemetry data on flights with high apogees or long range will become more important in the coming years. Improvements on the ground equipment and telemetry stations are necessary to serve the demands of future experiments. 


\title{
Appendix A \\ Acronym List
}

\author{
BEXUS Balloon Experiments for University Experiments \\ BIRD Bi-spectral IR Detection \\ CLA Centro de Lançamento de Alcântara \\ CLBI Centro de Lançamento da Barreira do Inferno \\ DCTA Departamento de Ciência e Tecnologia Aeroespacial \\ DLR Deutsches Zentrum für Luft- und Raumfahrt \\ EADS European Aeronautic Defence and Space Company \\ ECOMA Existence and Charge State of Meteoric Dust Grains in the Middle Atmosphere \\ ESA European Space Agency \\ ESRANGE European Space and Sounding Rocket Range \\ FM Frequency Modulation \\ GPS Global Position System \\ HIFiRE Hypersonic International Flight Research Experimentation \\ IABG Industrieanlagen-Betriebsgesellschaft $\mathrm{mbH}$ \\ IAE Instituto de Aeronaútica e Espaço \\ ISS International Space Station \\ MAPHEUS Materialphysikalische Experimente unter Schwerelosigkeit \\ MORABA Mobile Raketenbasis \\ PCM Pulse Code Modulation \\ PM Phase Modulation \\ RADAR Radio Detection and Ranging \\ REXUS Rocket-borne Experiments for University Students \\ RF Radio Frequency \\ RIR Range Instrumentation RADAR \\ SHEFEX Sharp Edge Flight Experiment \\ SNSB Swedish National Space Board \\ STERN Studentische Experimental-Raketen \\ TC Telecommand \\ TEXUS Technologische Experimente Unter Schwerelosigkeit \\ TM Telemetry \\ TT\&C Telemetry, Tracking \& Command \\ TV Television \\ VLM Veículo Lançador de Microsatélites \\ VSB Veículo de Sondagem Booster - 30 \\ WADIS Wellenausbreitung und Dissipation in der Mittleren Atmosphäre
}

\section{Appendix B \\ Glossary}

Launcher

Microgravity
Launch rail to launch sounding rockets.

The term micro-g environment or microgravity is more or less a synonym for weightlessness and zero-g, but indicates that g-forces are not quite zero but just very small

9

American Institute of Aeronautics and Astronautics 


\section{Payload}

Rocket

Science Payload
All modules above motoradapter including experiments, service system and recovery system

Complete Rocket Vehicle.

All scientific modules including the experiments

\section{References}

${ }^{1}$ Brattli, A., Lie-Svendsen, Ø., Svenes, K., Hoppe, U.-P., Strelnikova, I. Rapp, M., Latteck, R., and Friedrich M., “The ECOMA 2007 campaign: rocket observations and numerical modeling of aerosol particle charging and plasma depletion in a PMSE/NLC layer”, Annales Geophysicae, 27, 781-796, 2009.

${ }^{2}$ Baumgarten, G., Fiedler, J., Fricke, K.H., Gerding, M., Hervig, M., Hoffmann, P., Müller, N., Pautet, P.-D., Rapp, M., Robert, C., Rusch, D., von Savigny, C., and Singer, W., "The noctilucent cloud (NLC) display during the ECOMA/MASS sounding rocket flights on 3 August 2007: morphology on global to local scales”, Annales Geophysicae, 27, 953-965, 2009.

${ }^{3}$ Rapp, M., Strelnikova, I., Strelnikov, B., Hoffmann, P., Friedrich, M., Gumbel, J., Megner, L., Hoppe, U.-P., Robertson, S., Knappmiller, S., Wolff, M., and Marsh, D., "Rocket-borne in situ measurements of meteor smoke: Charging properties and implications for seasonal variation”, Journal of Geophysical Research, Vol. 115, D00I16, 2010.

${ }^{4}$ Rapp, M., "Charging of mesospheric aerosol particles: the role of photodetachment and photoionization from meteoric smoke and ice particles,” Annales Geophysicae, 27, 2417-2422, 2009.

${ }^{5}$ Forke, R., Kuhl, R., “Quantus-III - Joint DLR Project explores Giant Atoms in Microgravity”, DLR Countdown Newsletter, 14, 2011-01.

${ }^{6}$ Stamminger, A., Ettl, J., Jung, W., Grosse, J., “MAIUS User Manual”, DLR, 2012-04-20

${ }^{7}$ Kemi, S., Promaa, L., Schmidt, A., Turner, P., "Eurolaunch - A DLR and SSC Cooperation for Sounding Rocket and Balloon Missions”, SpaceOps, 2012-06

${ }^{8}$ Dolvin, D.J., "Hypersonic International Flight Research and Experimentation (HIFiRE) Fundamental Sciences and Technology Development Strategy", AIAA-2008-2581, 15 ${ }^{\text {th }}$ AIAA / AAAF international Conference on Space Planes and Hypersonic Systems and Technologies, 2008

${ }^{9}$ Boyce, R.R., Tirtey, S.C., Brown, L., Creagh, M., Ogawa, H., “SCRAMSPACE: Scramjet-based Access-to-Space Systems”, AIAA-2011-2297, 17 ${ }^{\text {th }}$ AIAA International Space Ples and Hypersonic Systems and Technologies Conference, 2011 